\title{
PSII photochemistry responses to drought stress in autochthonous and modern sweet cherry cultivars
}

\author{
I. MIHALJEVIĆ+, M. VILJEVAC VULETIĆ, V. TOMAŠ, D. HORVAT, Z. ZDUNIĆ, and D. VUKOVIĆ \\ Agricultural Institute Osijek, Južno predgrađe 17, HR-31000 Osijek, Croatia
}

\begin{abstract}
In this study, the JIP test was used to assess the drought tolerance of two sweet cherry cultivars (Prunus avium L.) (modern and autochthonous). Plants were exposed to progressive drought by withholding water and their fast $(<1 \mathrm{~s})$ chlorophyll fluorescence kinetics was evaluated. JIP test analysis showed that drought stress caused a greater decrease in performance indices $\left(\mathrm{PI}_{\mathrm{ABS}}\right.$ and $\left.\mathrm{PI}_{\text {total }}\right)$ in a modern cultivar, as compared to an autochthonous one. Our results suggest that limited reoxidation of primary quinone electron acceptor $\left(\mathrm{Q}_{\mathrm{A}}\right)$, higher amount of secondary quinone electron acceptor $\left(\mathrm{Q}_{\mathrm{B}}{ }^{-}\right)$nonreducing reaction centres, or inhibition of the electron transport between $\mathrm{Q}_{\mathrm{A}}$ and $\mathrm{Q}_{\mathrm{B}}$, decreased more seriously the photosynthetic performance of the modern cultivar. Further, higher positive L- and K-bands observed for the modern cultivar also suggest lower energetic connectivity between PSII units and increased inhibition of oxygenevolving complex over autochthonous cultivar. Our results suggest that the autochthonous cultivar Crveni hrušt had better photosynthetic performance under drought conditions, compared to the modern cultivar New Star.
\end{abstract}

Keywords: chlorophyll a fluorescence; chlorophyll content; malondialdehyde; photosynthesis; sweet cherry; water content.

\section{Introduction}

Fruit productions are highly dependent on water availability. In many agricultural areas, recent climate change is a serious threat and drought is a major limitation for tree growth and productivity worldwide. Previous research demonstrated that drought stress inhibits vegetative growth (Tsuchida et al. 2011, Blanco et al. 2020) and

\section{Highlights}

- The photosynthetic performance was higher in the autochthonous sweet cherry cultivar than in the modern

- Drought caused higher damage to PSII oxygen-evolving complex in the modern cultivar

- Higher oxidative damage was found in the modern cultivar
Received 31 May 2021

Accepted 17 September 2021

Published online 7 October 2021

Corresponding author

e-mail: ines.mihaljevic@poljinos.hr

Abbreviations: ABS/RC - absorption flux (of PSII antenna Chl) per RC; Chl - chlorophyll; DAS - days after stress (drought application); $\mathrm{ET}_{0} / \mathrm{ABS}\left(\varphi_{\mathrm{E} 0}\right)$ - quantum yield of electron transport from $\mathrm{Q}_{\mathrm{A}}^{-}$to $\mathrm{PQ} ; \mathrm{DI}_{0} / \mathrm{RC}$ - dissipation flux per $\mathrm{RC} ; \mathrm{DM}-\mathrm{dry}$ mass; $\mathrm{ET}_{0} / \mathrm{RC}$ - electron transport flux per $\mathrm{RC} ; \mathrm{ET}_{0} / \mathrm{TR}_{0}\left(\psi_{\mathrm{E} 0}\right)$ - probability that a trapped exciton moves an electron into the electron transport chain beyond $\mathrm{Q}_{\mathrm{A}} ; \mathrm{F}_{0}$ - minimum fluorescence, when all PSII RCs are open; FM - fresh mass; $\mathrm{F}_{\mathrm{m}}$ - maximum fluorescence, when all PSII RCs are closed; $\mathrm{F}_{\mathrm{v}}$ - maximal variable fluorescence; $\mathrm{F}_{\mathrm{v}} / \mathrm{F}_{0}$ - the ratio between the trapping flux and energy dissipation flux of PSII; $F_{v} / F_{m}$ - maximum quantum yield of PSII photochemistry; $\mathrm{M}_{0}$ - approximated initial slope of the fluorescence transient; $\mathrm{MDA}$ - malondialdehyde content; OEC - oxygen-evolving complex; $\mathrm{PI}_{\mathrm{ABS}}$ - performance index for energy conservation from photons absorbed by PSII until the reduction of intersystem electron acceptors; $\mathrm{PI}_{\text {total }}$ - performance index for energy conservation from photons absorbed by PSII until the reduction of PSI end acceptors; PQ - plastoquinone; $\mathrm{PQH}_{2}$ - plastoquinol; $\mathrm{RC}$ - reaction centre; $\mathrm{RE}_{0} / \mathrm{ABS}\left(\varphi_{\mathrm{R} 0}\right)$ - quantum yield of electron transport from $\mathrm{Q}_{\mathrm{A}}^{-}$to final PSI acceptors; $\mathrm{RE}_{0} / \mathrm{ET}_{0}\left(\delta_{\mathrm{R} 0}\right)$ - efficiency with which an electron can move from the reduced intersystem electron acceptors to the PSI end electron acceptors; $\mathrm{RE}_{0} / \mathrm{RC}$ - electron flux reducing end electron acceptors at the PSI acceptor side per reaction centre; ROS - reactive oxygen species; $\mathrm{S}_{\mathrm{m}}$ - normalized total complementary area above the OJIP transient (reflecting single-turnover $\mathrm{Q}_{\mathrm{A}}$ reduction events); $\mathrm{TR}_{0} / \mathrm{RC}$ - trapping flux per PSII RC; $\mathrm{V}_{\mathrm{I}}-$ relative variable fluorescence at $30 \mathrm{~ms}$ (I-step); $\mathrm{V}_{\mathrm{J}}$ - relative variable fluorescence at $2 \mathrm{~ms}$ (J-step); $\mathrm{V}_{\mathrm{OP}}$ - relative variable fluorescence between O- and P-steps; $\mathrm{WC}$ - water content; $\mathrm{W}_{\mathrm{OJ}}$ - relative variable fluorescence between $\mathrm{O}$ - and J-steps; $\mathrm{W}_{\mathrm{OK}}$ - relative variable fluorescence between O- and K-steps.

Conflict of interest: The authors declare that they have no conflict of interest. 
reduces fruit yield and quality (Pérez-Pérez et al. 2008). Under drought stress conditions, many morphological and physiological processes in plants, such as water content, membrane stability, and photosynthetic activity, are negatively affected (Abid et al. 2018). Plant stress responses are usually accompanied by changes in structure and function of the photosynthetic apparatus where PSII plays an important role in the response of photosynthesis to abiotic stress (Gururani et al. 2015). Drought stress limits the photosynthetic activity by closing the stomata, thereby decreasing $\mathrm{CO}_{2}$ fixation (Stirbet et al. 2018). According to Flexas and Medrano (2002), under moderate drought conditions, the decrease in photosynthesis is caused by stomatal limitation, while severe drought reduces photosynthetic rates by decreasing the ribulose1,5-bisphosphate (RuBP) synthesis, Rubisco activity thereby inhibits $\mathrm{CO}_{2}$ assimilation. Previous studies have shown that drought causes damage to the oxygen-evolving complex (OEC) (Gupta 2020), a decrease in electron transport rate, degradation of D1 protein (Batra et al. 2014), leading to the inactivation of the PSII reaction centre and inhibition in PSII activity. According to $\mathrm{Ma}$ et al. (2015), progressive drought provokes an imbalance between the energy absorbed by the source and the energy consumed by the metabolic sinks, leading to the formation of reactive oxygen species (ROS), where xanthophyll cycle-dependent thermal dissipation and the Mehler reaction are the most important pathways for dissipation excess energy from apple leaves. The photosynthetic efficiency of the plants, under stress conditions, can be estimated by the analysis of the polyphasic fast Chl fluorescence transient. The different steps of the polyphasic fluorescence transient are labelled as $\mathrm{O}, \mathrm{J}$, I, and $\mathrm{P}$, and the shape of the transient reflects plant sensitivity to changes in different environmental conditions (Kalaji et al. 2016). Some authors reported the use of the so-called L- and K-bands, calculated from the OJIP transient, which can be used as indicators of stress (Yusuf et al. 2010, Redillas et al. 2011, Paunov et al. 2018). The JIP test analysis of the OJIP transient, developed by Strasser and Strasser (1995), is often used as a tool for detection and evaluation of plant tolerance to various abiotic stresses, e.g., salt stress (Zushi and Matsuzoe 2017), heat stress (Jedmowski and Brüggemann 2015), cold (Franić et al. 2020), and drought stress (Dąbrowski et al. 2019). Earlier studies have demonstrated that drought stress has negative effects on the efficiency of PSII, as indicated by changes in Chl fluorescence parameters, thus this method is useful for screening genotypes for the selection of droughttolerant cultivars (Guha et al. 2013, Arslan et al. 2020). Since the drought will become more frequent and severe in the future, due to climate changes, many efforts have been made to alleviate its impact on food production and to increase crop stability (Cattivelli et al. 2008). One of the strategies to reduce the impact of drought on production is a selection of drought-tolerant cultivars. Sweet cherry is an important fruit growing worldwide, with many health benefits (Kelley et al. 2018). Over the past decades, much work has been done for the revitalization of old autochthonous fruit cultivars and the popularization of their products in the local area. These autochthonous varieties have been cultivated for a long time and they have been adapted to the local conditions very well. They contribute to the preservation of biological and genetic diversity as well as the stability of the agroecosystems (Radoš et al. 2017). Therefore, they are very important for breeding programs as a source of genetic diversity (Mondini et al. 2009), because of their good biological and economic characteristics, which should be used in breeding and creation of new varieties. Since they represent a very important genetic potential for future breeding programs, it is necessary to evaluate their commercial and agronomic traits. Although pomological and chemical characteristics (Radoš et al. 2017), as well as molecular identification of these autochthonous sweet cherry cultivars (Krmpot et al. 2020) were already performed, there is still a lack of studies on autochthonous varieties, particularly mechanisms of tolerance to abiotic stress. Knowledge about the adaptation to specific environmental conditions is essential for the selection of suitable varieties for future fruit production. Thus, the objective of the present study was to investigate the performance of PSII photochemistry in one-year-old trees of two contrasting sweet cherry cultivars (autochthonous and modern) under drought stress. We studied the parameters derived from the fast Chl $a$ fluorescence kinetics, lipid peroxidation, as well as $\mathrm{Chl}$ and water content to evaluate drought stress response of sweet cherry trees and distinguish differences in drought tolerance of PSII function between the autochthonous and modern cultivars. Photosynthesis and photoprotective mechanisms are still not well understood for cherry trees (Prunus avium L.) during the drought period, and PSII photochemistry of the investigated autochthonous sweet cherry has not been previously studied. Thus, this work on sweet cherry leaves will provide information on the functional status of PSII in selected sweet cherry cultivars exposed to the drought.

\section{Materials and methods}

Plant material and experimental design: Two sweet cherry (Prunus avium L.) cultivars, one autochthonous (Crveni hrušt), and one commercial (New Star), were used for our experiment. Crveni hrušt is an autochthonous variety of unknown origin that is grown for a long time in Croatia (Požega Valley) and surrounding countries under the similar name (Crveni hrušt, Hrušt, Hrust). Despite the dominance of new, high-yielding cultivars, Crveni hrušt is still keeping its importance and is often grown in Croatia, but mostly in the backyards, as individual trees. New Star is a modern cultivar, one of the best mid-season cherry varieties, as well as one of the most represented in production in Croatia. One-year-old sweet cherry trees, grafted into rootstock Gysela 6, were grown in pots $(25 \mathrm{~L}$, one plant per pot). The potted substrate was composed of soil mixture: $65 \%$ white peat, $35 \%$ black peat, $150 \mathrm{~L}$ of clay per $\mathrm{m}^{3}, 1,500 \mathrm{~g}$ of nitrogen, phosphorous, and potassium fertilizer per $\mathrm{m}^{3}$. The pots were placed in a greenhouse 
located at the Agricultural Institute Osijek, Osijek, Croatia under semi-controlled conditions (mean air temperature on $3,5,7 \mathrm{~d}$ after stress (DAS): $25 / 16^{\circ} \mathrm{C}, 26 / 16^{\circ} \mathrm{C}, 25 / 15^{\circ} \mathrm{C}$ day/night; mean relative air humidity of $70 / 85 \%, 68 / 82 \%$, $70 / 80 \%$ day/night; natural irradiance). Ten potted plants of each cultivar were normally irrigated until the experiment onset. In the experiment, five potted plants served as a control treatment and they were continually irrigated with $2 \mathrm{~L}$ of water every day. Another five plants were set as drought treatment and we stopped watering them to impose drought conditions. The experiment ended when wilting symptoms appeared on nonirrigated plants (drought treatment). All measurements and samplings were performed at 3,5 , and $7 \mathrm{~d}$ after drought application (DAS).

Chl fluorescence measurements were conducted on two leaves per plant on five plants for each cultivar and treatment. Measurements were made in vivo, using a Handy PEA (Hansatech Instruments Ltd., Norfolk, UK), on the $5^{\text {th }}$ and $6^{\text {th }}$ fully expanded leaves, which were not overlapping each other, on sunny days (between 08:00 to 10:00 h). After 30-min adaptation to darkness, leaves were illuminated with a 1-s pulse of saturating light intensity of 3,000 $\mu \mathrm{mol}$ (photon) $\mathrm{m}^{-2} \mathrm{~s}^{-1}$. The fluorescence data were analyzed according to the JIP test, see reviews by Strasser et al. (2004), Stirbet and Govindjee (2011), Goltsev et al. (2016). Twenty JIP parameters were selected to monitor the changes that occurred in the photosynthetic apparatus. Definitions and calculations of the JIP test parameters used in the present study are given in the Appendix. OJIP transients in plants exposed to drought treatment and control unstressed plants were measured and analyzed. To compare the Chl fluorescence transients from two sweet cherry cultivars, we double normalized data between $\mathrm{F}_{0}$ and $\mathrm{F}_{\mathrm{m}}(\mathrm{O}-\mathrm{P}$ steps). These normalized OJIP transients represent the kinetics of the relative variable fluorescence $\left[\mathrm{V}_{\mathrm{OP}}=\left(\mathrm{F}_{\mathrm{t}}-\mathrm{F}_{0}\right) /\left(\mathrm{F}_{\mathrm{P}}-\mathrm{F}_{0}\right)\right]$ and were plotted on a logarithmic time scale. For the analysis of drought-induced changes in the OJIP curve, two differential curves were calculated separately to compare changes occurring during $\mathrm{O}-\mathrm{P}$ transients: the L- and K-bands. The curves for these bands were obtained by subtracting the normalized fluorescence values between $\mathrm{O}-\mathrm{K}$, and respectively, $\mathrm{O}-\mathrm{J}$, recorded in control plants from those recorded in plants under drought stress. Normalization between the O- and K-steps $\left[\mathrm{W}_{\mathrm{OK}}=\left(\mathrm{F}_{\mathrm{t}}-\mathrm{F}_{0}\right) /\left(\mathrm{F}_{\mathrm{K}}-\mathrm{F}_{0}\right)\right]$ was used to calculate the L-band $(\sim 150 \mu \mathrm{s}): \triangle \mathrm{W}_{\mathrm{OK}}=\mathrm{W}_{\mathrm{OK} \text { (drought) }}-\mathrm{W}_{\mathrm{OK} \text { (control) }}$. Normalization between the $\mathrm{O}$ - and J-steps $\left[\mathrm{W}_{\mathrm{OJ}}=\left(\mathrm{F}_{\mathrm{t}}-\mathrm{F}_{0}\right) /\left(\mathrm{F}_{\mathrm{J}}-\mathrm{F}_{0}\right)\right]$ was used to calculate the K-band $(\sim 300 \mu \mathrm{s}): \Delta \mathrm{W}_{\mathrm{OJ}}=$ $\mathrm{W}_{\mathrm{OJ}(\text { drought) }}-\mathrm{W}_{\mathrm{OJ}(\text { control) }}$ (Yusuf et al. 2010).

Chl content: After the measurement of the Chl fluorescence of sweet cherry leaves at 3,5, and 7 DAS, individual leaves were sampled and used for further analyses of the $\mathrm{Chl}$ content. Photosynthetic pigments were extracted from about $0.1 \mathrm{~g}$ of liquid-nitrogen-powdered leaves with absolute acetone in the presence of magnesium hydroxide carbonate. Spectrophotometrically (Specord 200, Analytik, Jena, Germany) recorded absorbances at
470, 647, and $663 \mathrm{~nm}$ were used for total chlorophyll [Chl $(a+b)]$ calculation according to Lichtenthaler (1987).

Water content (WC): The fraction of the same leaves used for measuring Chl fluorescence were sampled from control and drought-treated plants of each cultivar and weighed to obtained fresh leaves mass (FM). The samples were then oven-dried at $75^{\circ} \mathrm{C}$ overnight and weighed again to determine the dry mass (DM). The water content was measured by using the following equation: WC [\%] = $[(\mathrm{FM}-\mathrm{DM}) / \mathrm{FM}] \times 100$ (Kumar et al. 2017). Each sample was measured in biological triplicate.

MDA content: Lipid peroxidation was expressed as the MDA content and determined as 2-thiobarbituric acid (TBA)-reactive metabolites using the method of Verma and Dubey (2003). Leaves were harvested after measuring Chl $a$ fluorescence and a bulk sample of the same leaves for each cultivar and treatment was used for the analysis. Fresh tissue leaf powder $(0.20 \mathrm{~g})$ was homogenized in $1 \mathrm{ml}$ of $0.1 \%(\mathrm{w} / \mathrm{v})$ trichloracetic acid (TCA). The homogenate was centrifuged at $12,000 \mathrm{rpm}$ for $15 \mathrm{~min}$ at $4^{\circ} \mathrm{C}$. The reaction mixture was prepared by mixing $0.5 \mathrm{~mL}$ of the supernatant and $1 \mathrm{~mL}$ of $0.5 \%$ thiobarbituric acid (TBA) in $20 \%$ TCA. The reaction mixture was heated at $95^{\circ} \mathrm{C}$ for $30 \mathrm{~min}$ in a heating block and then cooled in an ice bath. The samples were then centrifuged at $14,000 \times g$ for $15 \mathrm{~min}$. The absorbance of the supernatant was read at 532 and $600 \mathrm{~nm}$ (Specord 200, Analytik, Jena, Germany). An extinction coefficient of $155 \mathrm{mM}^{-1} \mathrm{~cm}^{-1}$ was used to calculate the amount of MDA.

Statistical analysis: Statistical differences between control and drought-treated plants and cultivars, at three time points $(3,5$, and $7 \mathrm{DAS})$, were compared by analysis of variance with post-hoc Fisher's least significant difference test (LSD). Differences were considered statistically significant when $p<0.05$. Data are means \pm SE of ten biological replicates for parameters, five for chlorophyll content and MDA, and three for water content.

\section{Results}

To understand the mechanisms and to trace changes in the photosynthetic electron transport chain, we used twenty parameters from the JIP test. Significant differences under drought conditions were found between investigated sweet cherry cultivars in most of the JIP test parameters, as well as between the days of measurement and cultivars.

Fast Chl fluorescence (OJIP) curves shape: There are clear differences in the shape of OJIP transient between cultivars in drought treatment but no differences between OJIP curves in control plants (Fig. 1A). The most pronounced changes were in the modern cultivar New Star, while in the autochthonous cultivar (Crveni hrušt) OJIP shape was only slightly changed. The J- and I-steps increased under increasing drought stress, and they were more pronounced in New Star cultivar compared to Crveni hrušt (Fig. 1B). The relative variable fluorescence 
at $2 \mathrm{~ms}\left(\mathrm{~V}_{\mathrm{J}}\right)$ and the variable fluorescence at $30 \mathrm{~ms}\left(\mathrm{~V}_{\mathrm{I}}\right)$ significantly increased under drought conditions in both cultivars from 5 DAS but significantly higher values were observed in plants of modern cultivar New Star than in plants of traditional cultivar Crveni hrušt. In this study, the kinetic difference $\Delta \mathrm{V}_{\mathrm{OK}}$ and $\Delta \mathrm{V}_{\mathrm{OJ}}$ made the $\mathrm{L}$ - and $\mathrm{K}$-bands visible. Both investigated cultivars presented L-bands (obtained at $\sim 0.15 \mathrm{~ms}$ ) and K-band (obtained at $\sim 0.3 \mathrm{~ms}$ ) with positive amplitudes after submission to drought.

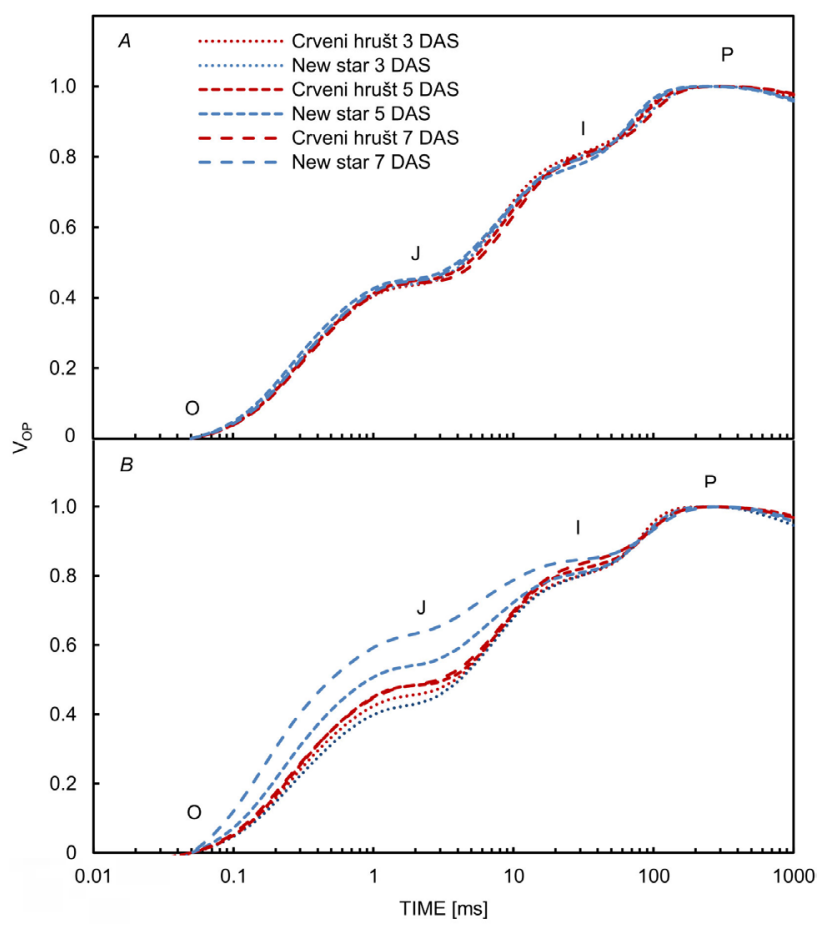

Fig. 1. Chlorophyll $a$ fluorescence curves (OJIP transients) of leaves of two sweet cherry cultivars after 3,5 , and 7 DAS. O, J, $\mathrm{I}$, and $\mathrm{P}$ indicate the specific steps in chlorophyll $a$ fluorescence transient in $(A)$ control and $(B)$ drought-treated sweet cherry plants.
Higher K-bands were obtained for the modern cultivar New Star and similarly, a higher positive amplitude of the L-bands was observed also for the modern cultivar New Star when compared to autochthonous cultivar Crveni hrušt, at all three times of measurement (Fig. 2).

Chl fluorescence parameters: Drought stress caused a significant increase in the initial fluorescence intensity $\left(\mathrm{F}_{0}\right)$ in both investigated cultivars under drought conditions. The increase of $F_{0}$ in modern cultivar New Star was observed earlier, from 5 DAS, and it was more pronounced than in autochthonous Crveni hrušt (Fig. 3A). Drought significantly reduced the values of parameter maximal fluorescence intensity $\left(\mathrm{F}_{\mathrm{m}}\right)$, as well as the maximal variable fluorescence $\left(F_{v}\right)$, only in modern cultivar New Star from the $5^{\text {th }}$ day of drought treatment (Fig. 3B,C). The normalized total complementary area above the OJIP transient $\left(\mathrm{S}_{\mathrm{m}}\right)$ in drought treatment significantly decreased compared with those of the controls in both cultivars at 7 DAS but was significantly higher in autochthonous cultivar Crveni hrušt (Fig. 3F). A decrease in the values of the ratio between the trapping flux and energy dissipation flux of PSII $\left(\mathrm{F}_{\mathrm{v}} / \mathrm{F}_{0}\right)$ was observed in modern cultivar New Star from 5 DAS, while in autochthonous cultivar Crveni hrušt the significant decrease was observed later at 7 DAS. The decrease of this parameter was significantly higher in New Star compared to autochthonous Crveni hrušt (Fig. 3G). The initial slope of the fluorescence transient $\left(\mathrm{M}_{0}\right)$ increased in the case of both cultivars from 5 DAS with significantly higher values in New Star (Fig. 3H).A significant decrease of the parameter evaluating maximum quantum yield of primary PSII photochemistry $\left(F_{\mathrm{v}} / \mathrm{F}_{\mathrm{m}}=\mathrm{TR}_{0} / \mathrm{ABS}\right)$ between control and drought-stressed plants was observed in modern cultivar New Star from 5 DAS, while the autochthonous cultivar Crveni hrušt showed a significant decrease at 7 DAS (Fig. 4A). The parameter expressing quantum yield for electron transport from $\mathrm{Q}_{\mathrm{A}}{ }^{-}$to $\mathrm{PQ}\left(\mathrm{ET}_{0} / \mathrm{ABS} ; \varphi_{\mathrm{E} 0}\right)$ decreased under drought in both cultivars from 5 DAS but was significantly higher in modern cultivar New Star (Fig. 4B). The probability that a trapped exciton moves an electron into the electron
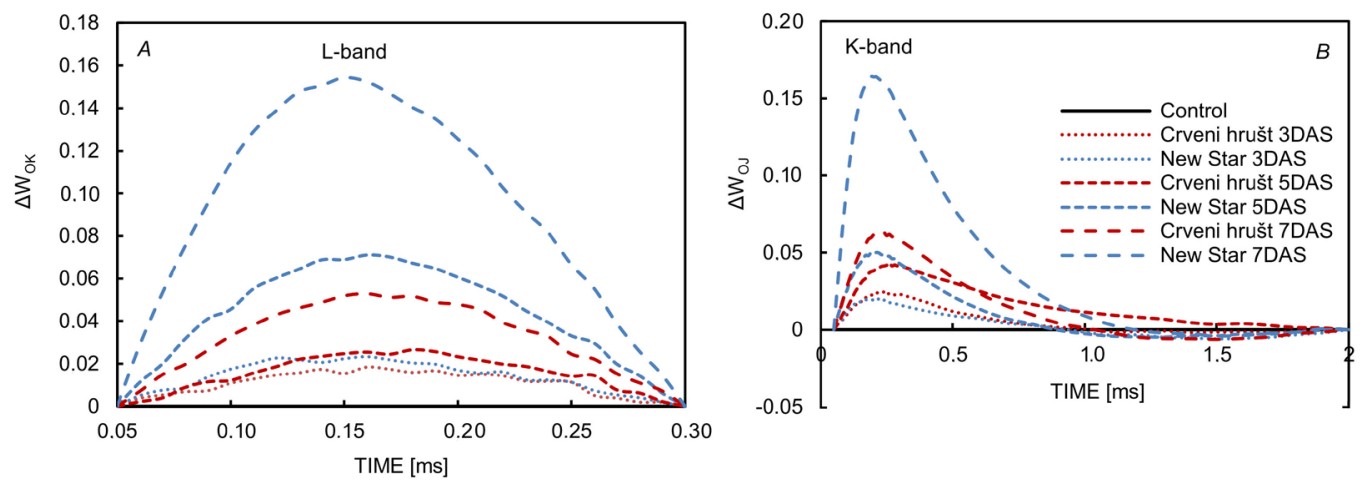

Fig. 2. (A) L-band: changes in $\mathrm{O}-\mathrm{K}$ phase relative variable fluorescence intensity $\left[\Delta \mathrm{W}_{\mathrm{OK}}=\mathrm{V}_{\mathrm{OK}(\mathrm{drought})}-\mathrm{V}_{\mathrm{OK}(\text { control) }}\right]$, (B) $\mathrm{K}$-band: changes in $\mathrm{O}-\mathrm{J}$ phase relative variable fluorescence intensity $\left[\Delta \mathrm{W}_{\mathrm{OJ}}=\mathrm{V}_{\mathrm{OJ} \text { (drought) }}-\mathrm{V}_{\mathrm{OJ}(\text { control) }}\right]$, in two sweet cherry cultivars on 3, 5, and 7 DAS. The difference kinetics were calculated from the comparisons of the drought-stressed and control plants. 


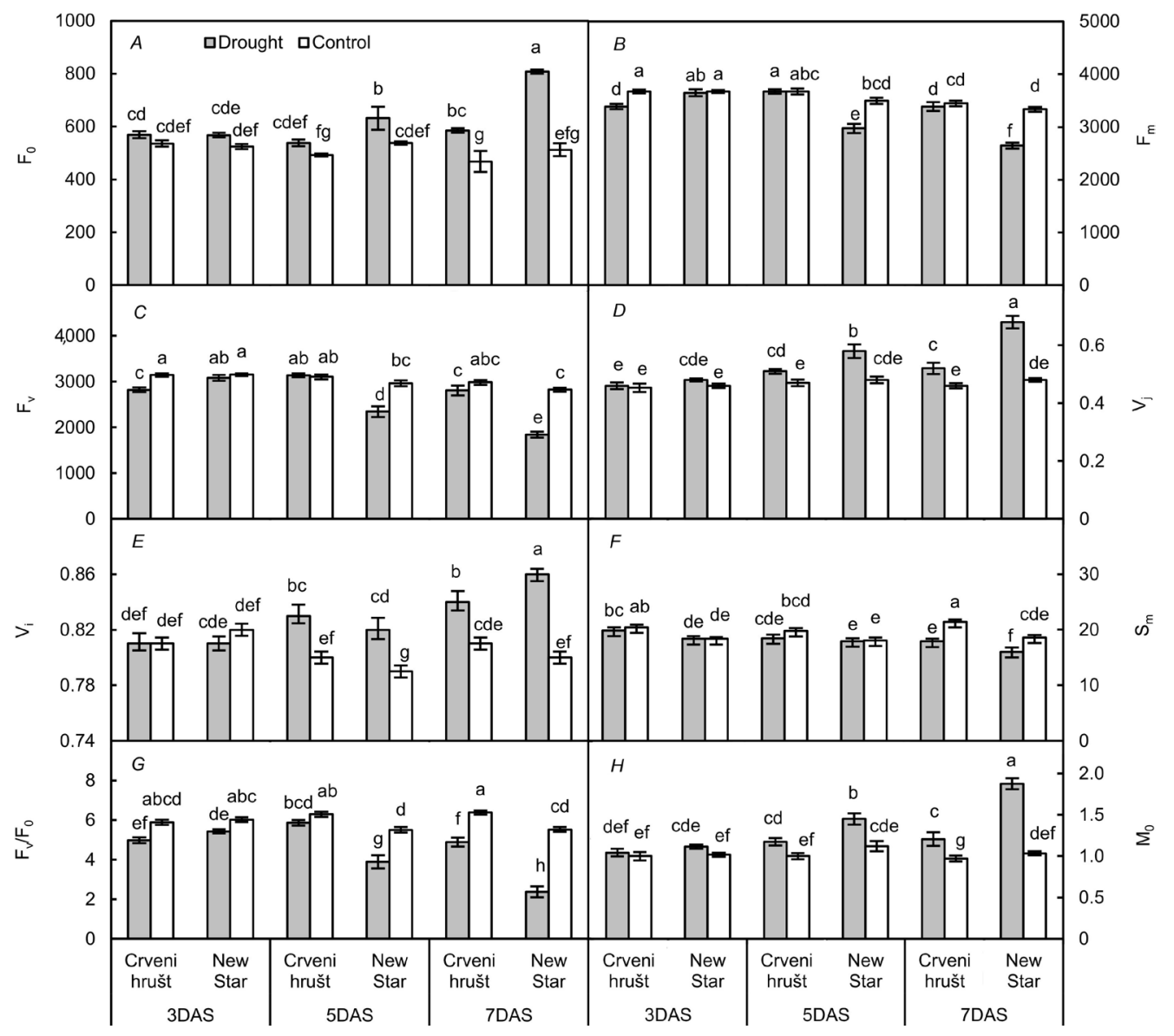

Fig. 3. OJIP-derived parameters: $(A) \mathrm{F}_{0},(B) \mathrm{F}_{\mathrm{m}},(C) \mathrm{F}_{\mathrm{v}},(D) \mathrm{V}_{\mathrm{J}},(E) \mathrm{V}_{\mathrm{I}},(F) \mathrm{S}_{\mathrm{m}},(G) \mathrm{F}_{\mathrm{v}} / \mathrm{F}_{0}$, and $(H) \mathrm{M}_{0}$ measured at 3, 5, and 7 DAS (day after stress) in control and drought-stressed sweet cherry cultivars (Crveni hrušt and New Star). The definition for these parameters is in the Appendix. Data in the figures indicate mean of ten replicates. Different letters indicate significant difference between cultivars and treatments at $p<0.05$.

transport chain beyond $\mathrm{Q}_{\mathrm{A}}^{-}\left(\mathrm{ET}_{0} / \mathrm{TR}_{0} ; \psi_{\mathrm{E} 0}\right)$ decreased at 3 DAS in cultivar New Star, while in cultivar Crveni hrušt at 5 DAS (Fig. 4C). We also observed that the parameter reflecting the efficiency with which an electron from $\mathrm{PQH}_{2}$ is transferred to final PSI acceptors $\left(\mathrm{RE}_{0} / \mathrm{ET}_{0}\right.$; $\left.\delta_{\mathrm{R} 0}\right)$ was constant in both cultivars with no significant differences between control and drought-treated plants (Fig. 4D). Furthermore, the parameter evaluating the quantum yield for reduction of end electron acceptors at the PSI acceptor side $\left(\mathrm{RE}_{0} / \mathrm{ABS} ; \varphi_{\mathrm{R} 0}\right)$ of drought-treated plants significantly decreased at 7 DAS from control plants in both investigated cultivars, but without the significant difference between cultivars (Fig. 4E). The significant increase of parameters representing the absorption flux of PSII antenna per RC (ABS/RC) and the dissipation energy flux per $\mathrm{RC}\left(\mathrm{DI}_{0} / \mathrm{RC}\right)$ was observed earlier in modern cultivar New Star at 5 DAS, while in Crveni hrušt it took place at 7 DAS. Also, the highest increase of these parameters was found in modern cultivar New Star compared to autochthonous Crveni hrušt (Fig. 5A,D). The trapping per $\mathrm{RC}\left(\mathrm{TR}_{0} / \mathrm{RC}\right)$ increased in leaves of both cultivars at 5 DAS and prolonged at 7 DAS (Fig. 5B).
The electron transport flux per $\mathrm{RC}\left(\mathrm{ET}_{0} / \mathrm{RC}\right)$ of modern cultivar New Star decreased at 5 and 7 DAS, while values of that parameter in autochthonous cultivar Crveni hrušt did not significantly change (Fig. 5C). Electron flux reducing end electron acceptors at the PSI acceptor side per $\mathrm{RC}\left(\mathrm{RE}_{0} / \mathrm{RC}\right)$ showed significant changes only in New Star after $7 \mathrm{~d}$ of exposure to drought relative to controls (Fig. 5E). Under drought treatment, the performance index on absorption basis $\left(\mathrm{PI}_{\mathrm{ABS}}\right)$ decreased in both cultivars at 3 DAS, while the performance index for energy conservation from exciton to the reduction of PSI end acceptors $\left(\mathrm{PI}_{\text {total }}\right)$ significantly decreased after 3 DAS in Crveni hrušt while in New Star at 5 DAS. Values of these parameters decreased more for modern cultivar New Star than for autochthonous Crveni hrušt (Fig. 6).

Total Chl content: The mean values of total Chl content in drought-treated leaves were significantly lower than in control leaves only in modern cultivar New Star at 7 DAS. The concentration of total $\mathrm{Chl}$ content in autochthonous cultivar Crveni hrušt under drought conditions increased at 3 and 5 DAS, while at 7 DAS, Chl content remained 


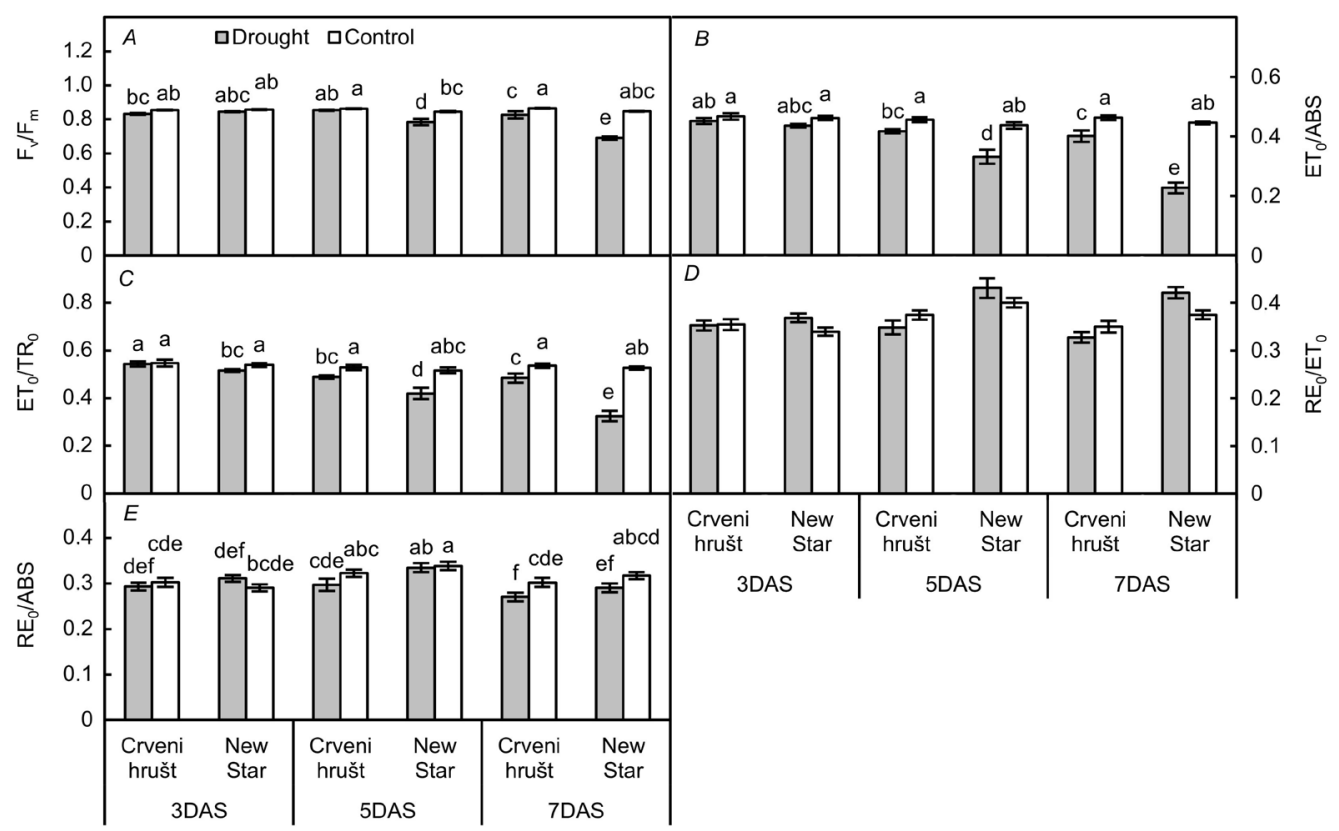

Fig. 4. OJIP-derived parameters: $(A) \mathrm{F}_{\mathrm{v}} / \mathrm{F}_{\mathrm{m}},(B) \mathrm{ET}_{0} / \mathrm{ABS},(C) \mathrm{ET}_{0} / \mathrm{TR}_{0},(D) \mathrm{RE}_{0} / \mathrm{ET}_{0}$, and $(E) \mathrm{RE}_{0} / \mathrm{ABS}$, measured at 3, 5, and $7 \mathrm{DAS}$ (day after stress) in control and drought-stressed sweet cherry cultivars (Crveni hrušt and New Star). The definition for these parameters is in the Appendix. Data in the figures indicate mean of ten replicates. Different letters indicate significant difference between cultivars and treatments at $p<0.05$.

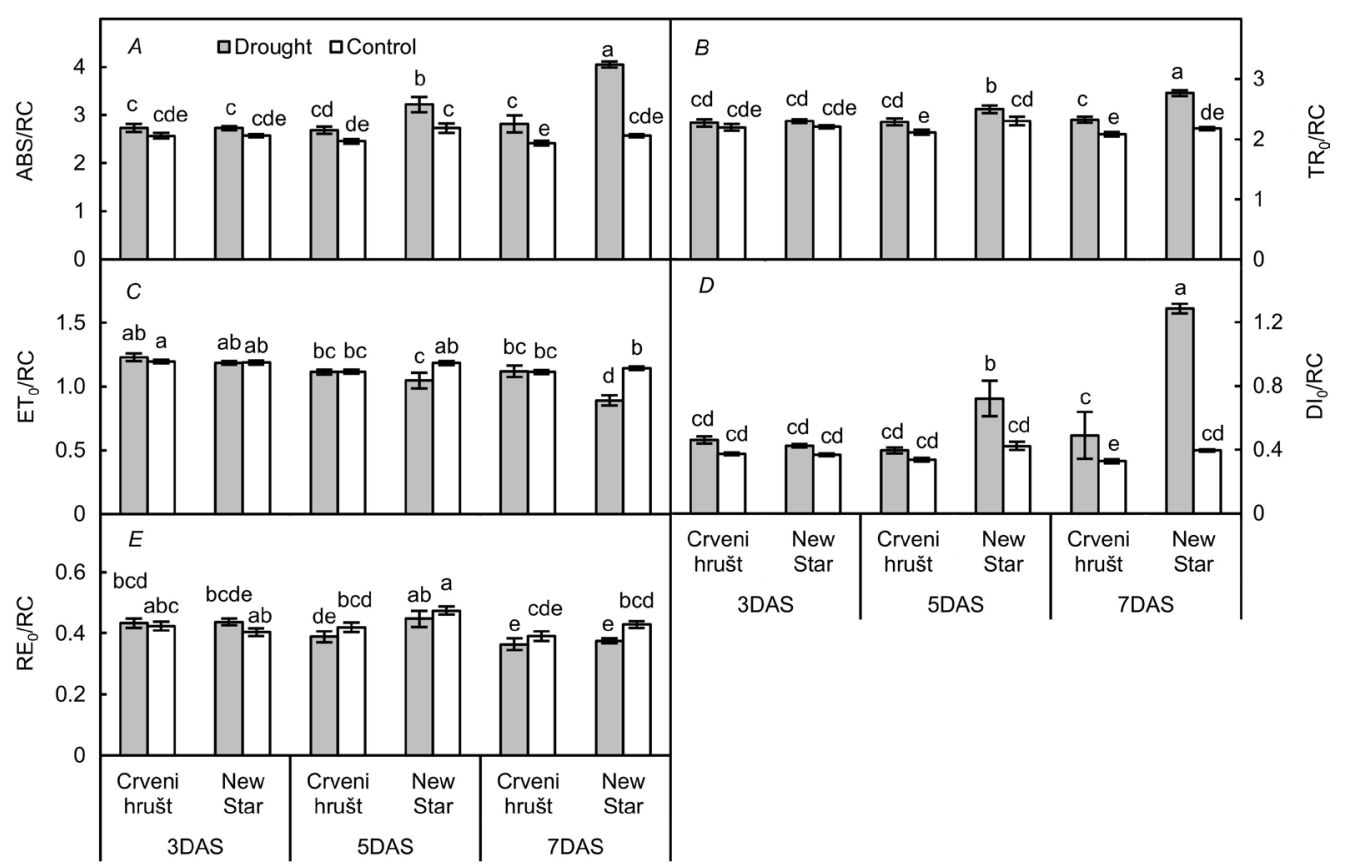

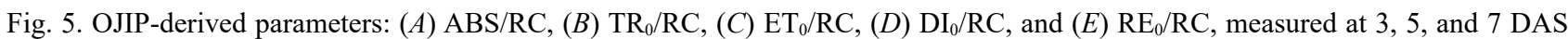
(day after stress) in control and drought-stressed sweet cherry cultivars (Crveni hrušt and New Star). The definition for these parameters is in the Appendix. Data in the figures indicate mean of ten replicates. Different letters indicate significant difference between cultivars and treatments at $p<0.05$.

unchanged in drought-stressed leaves compared to control (Fig. 7A).
MDA content: Variations in the MDA content under drought stress were observed only in modern cultivar 
New Star visualized as an increase in drought treatment compared to control at 3 DAS. Moreover, the MDA content

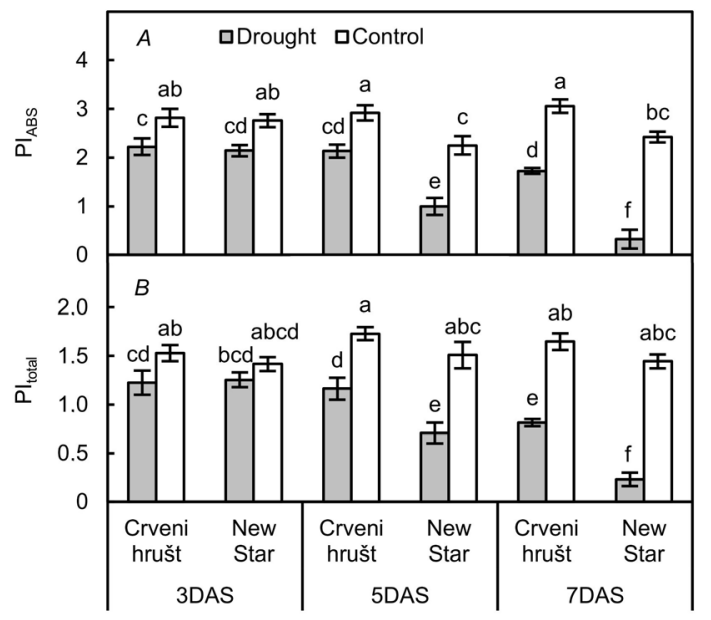

Fig. 6. OJIP-derived parameters: $(A) \mathrm{PI}_{\mathrm{ABS}}$ and $(B) \mathrm{PI}_{\text {total }}$ measured at 3,5 , and 7 DAS (day after stress) in control and droughtstressed sweet cherry cultivars (Crveni hrušt and New Star). The definition for these parameters is in the Appendix. Data in the figures indicate mean of ten replicates. Different letters indicate significant difference between cultivars and treatments at $p<0.05$.

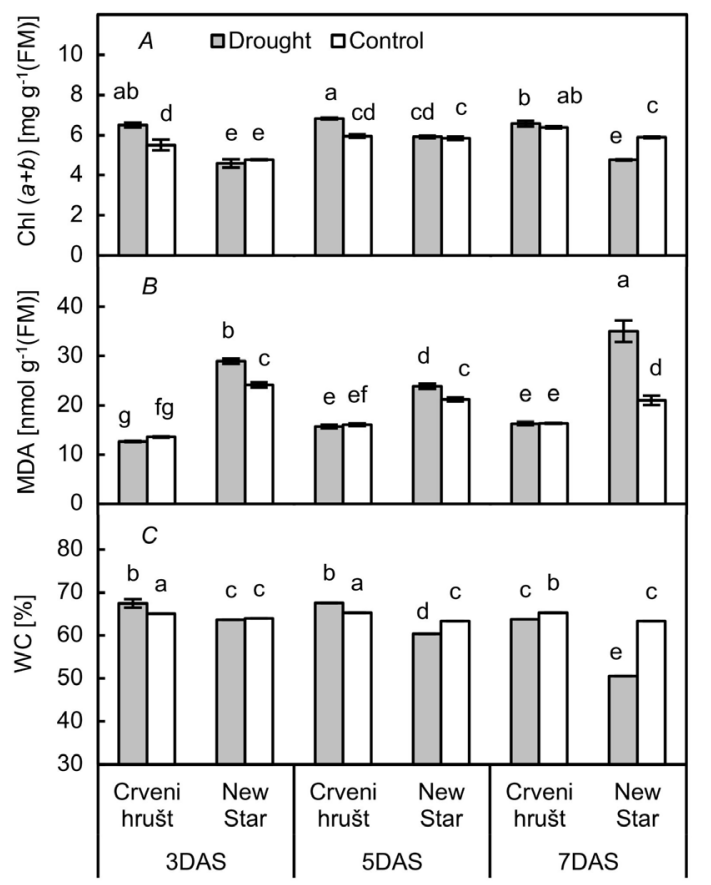

Fig. 7. (A) Total chlorophyll content $[\mathrm{Chl}(a+b)],(B)$ malondialdehyde content (MDA), and $(C)$ water content (WC) measured at 3, 5, and 7 DAS (day after stress) in control and drought-stressed sweet cherry cultivars (Crveni hrušt and New Star). Data in the figures indicate mean of five replicates for chlorophyll content and malondialdehyde and three replicates for water content. Different letters indicate significant difference between cultivars and treatments at $p<0.05$. of modern cultivar New Star was significantly higher than that of autochthonous cultivar Crveni hrušt during the whole experiment even in control leaves (Fig. 7B).

Water content (WC): The water content in the leaves of the modern cultivar New Star decreased significantly from 5 DAS. In the leaves of autochthonous cultivar Crveni hrušt, a significant increase in water content was recorded at 3 and 5 DAS. The significant decrease of water content in this cultivar was observed at 7 DAS (Fig. 7C).

\section{Discussion}

In our study, we used progressive drought stress in sweet cherry plants to induce changes in the light phase of photosynthesis. Obtained results showed that drought stress-induced changes, demonstrated by the JIP test, were different between two investigated sweet cherry cultivars. The effect of drought stress was reflected in the change of the OJIP curves of investigated cultivars and showed the differences between them. The $\mathrm{J}$ - (parameter $\mathrm{V}_{\mathrm{J}}$ ) and I-step (parameter $\mathrm{V}_{\mathrm{I}}$ ) gradually increased along with the increasing duration of drought. Considerable changes in fluorescence occurred at J- and I-steps in modern cultivar New Star, whereas only minor changes in fluorescence at J- and I-steps occurred in autochthonous cultivar Crveni hrušt. The higher increase in the J-step of modern cultivar New Star indicates the stronger decrease of electron transport on the acceptor side of PSII (Strasser 1997) and a large accumulation of reduced $\mathrm{Q}_{\mathrm{A}}{ }^{-}$in PSII RCs (Lopes et al. 2019). A higher increase at I-step of fluorescence transient curve observed in New Star at 7 DAS may be due to a higher accumulation of the amount of the $\mathrm{Q}_{\mathrm{B}}{ }^{-}$ nonreducing centres (Lazár 2006), which are unable to transfer electrons efficiently from electron acceptor $\mathrm{Q}_{\mathrm{A}}$ to $\mathrm{Q}_{\text {в }}$ (Lavergne 1982). These results are similar to previous findings which revealed a rise of $\mathrm{V}_{\mathrm{J}}$, which occurred in drought-stressed barley plants (Ghotbi-Ravandi et al. 2016). Under drought, Chl $a$ fluorescence analyses have shown positive values for L- and K-bands in both cultivars of sweet cherry. According to previous research (Strasser et al. 2004, Jedmowski et al. 2014) appearance of the $\mathrm{K}$-band indicates that drought stress caused partial inactivation of the oxygen-evolving complex (OEC), while the appearance of the L-band indicates lower PSII energetic connectivity of antennae of PSII RC units (Oukarroum et al. 2007, Stirbet 2013). Higher positive L-band observed in the leaves of modern cultivar New Star suggests less connectivity within the PSII units compared to autochthonous cultivar Crveni hrušt, while higher positive K-band of that cultivar suggests the reduced efficiency of OEC due to slower electron flow between OEC and acceptor side of the RC (Yusuf et al. 2010). This result indicates that autochthonous cultivar Crveni hrušt maintained better utilization of excitation energy and greater stability of the system when exposed to progressive drought. Similar positive L- and K-bands occurred in the leaves of Passiflora edulis L. (Gomes et al. 2012) and in the leaves of rubber trees (Falqueto et al. 2017) under drought conditions. $\mathrm{S}_{\mathrm{m}}$ represents the normalized area of the $\mathrm{Chl}$ fluorescence induction curve, it is proportional to 
the pool size of electron carriers. This parameter was significantly lower in drought-stressed leaves of both cultivars at $7 \mathrm{DAS}$, indicating the reduced transport from $\mathrm{Q}_{\mathrm{A}}^{-}$to $\mathrm{Q}_{\mathrm{B}}$, as it was observed in the drought-stressed apple leaves (Yuan et al. 2013). Since more light energy was used to reduce $\mathrm{Q}_{\mathrm{A}}$, this resulted in an increase of $\mathrm{M}_{0}$. The significant increase in the net rate of $\mathrm{RC}$ closure observed in New Star suggested that the reduction of $\mathrm{Q}_{\mathrm{A}}$ to $\mathrm{Q}_{\mathrm{A}}{ }^{-}$was higher under drought treatment in the leaves of New Star cultivar than in autochthonous Crveni hrušt. This finding is supported by previous results that the net rate of RC closure increased in drought-sensitive mung bean plants after exposure to drought (Bano et al. 2021). Significantly higher values of $F_{0}$ due to drought stress in New Star could occur because of a partial reduction of the $P Q$ pool in darkness. Increased value of $F_{0}$ was reported in drought-stressed mulberry plants (Guha et al. 2013). According to Kalaji et al. (2011), low values of $F_{m}$ indicate the accumulation of inactive RC at PSII, which was confirmed in our study, only in the leaves of modern cultivar New Star. In previous research, a large increase was observed in the parameters $\mathrm{ABS} / \mathrm{RC}, \mathrm{DI}_{0} / \mathrm{RC}$, and $\mathrm{TR}_{0} / \mathrm{RC}$ and a large decrease in $\mathrm{ET}_{0} / \mathrm{RC}$ and $\mathrm{PI}_{\mathrm{ABS}}$ in drought-sensitive plants of potato subjected to drought (Plich et al. 2020). Similarly, we also noticed the increase in parameters $\mathrm{ABS} / \mathrm{RC}, \mathrm{DI}_{0} / \mathrm{RC}$, and $\mathrm{TR}_{0} / \mathrm{RC}$ by drought in both cultivars, but these were more obvious in modern cultivar New Star. The higher values of $\mathrm{ABS} / \mathrm{RC}$ in New Star implied that a fraction of active reaction centres was more inactivated because of higher inhibition of electron transport from $\mathrm{Q}_{\mathrm{A}}^{-}$to $\mathrm{Q}_{\mathrm{B}}$, and transformation of $\mathrm{RCs}$ to 'silent' RCs (Yusuf et al. 2010). This corroborated with reduced values of $\mathrm{ET}_{0} / \mathrm{RC}$ in New Star under drought as it was observed in drought-stressed plants of Abies koreana (Je et al. 2018). Since the inactive centres could not trap photons, the increase in the rate of energy dissipation of untrapped excitations causes an increase of $\mathrm{DI}_{0} / \mathrm{RC}$ (Sousaraei et al. 2021). According to previous research, an increase in $\mathrm{ABS} / \mathrm{RC}$ and $\mathrm{TR}_{0} / \mathrm{RC}$ indicates that some $\mathrm{RCs}$ were inactivated due to inactivation of OEC as well as the transformation of active RCs to silent (Liang et al. 2019); an increase in $\mathrm{TR}_{0} / \mathrm{RC}$ can indicate impairment of the oxygen-evolving complex (Braga et al. 2020). In our study, we also observed higher increases of $\mathrm{TR}_{0} / \mathrm{RC}$ and higher $\mathrm{K}$ amplitude in cultivar New Star compared to Crveni hrušt. Significantly higher values of $\mathrm{DI}_{0} / \mathrm{RC}$ and decreased values of $\mathrm{ET}_{0} \mathrm{RC}$ in modern cultivar New Star showed that excess energy was dissipated, which is indicated as an adaptive strategy to reduce photodamage to photosynthetic apparatus (Akhter et al. 2021). Furthermore, a similar but more efficient strategy can be seen in cultivar Crveni hrušt, which resulted in untouched $\mathrm{ET}_{0} / \mathrm{RC}$ in drought-stressed leaves referring that this can be the base of its tolerance, implying that it could protect its photosynthetic apparatus through efficient utilizing absorbed light energy rather than through thermal dissipation. The parameter $F_{v} / F_{m}$ describing the efficiency of energy trapping in PSII reaction centres is the most commonly analyzed $\mathrm{Chl}$ fluorescence parameter. The more pronounced decline in $\mathrm{F}_{\mathrm{v}} / \mathrm{F}_{\mathrm{m}}$ ratio was observed in modern cultivar New Star and similar reducing trends were also observed in the parameter $F_{v} / F_{0}$. The parameter $F_{v} / F_{0}$ is very sensitive due to water deficit (Pereira et al. 2000). A higher decrease of this parameter in the modern cultivar New Star indicates inactivity of the water-splitting complex at the PSII donor side in this cultivar as was observed in wheat under salinity stress (Maswada et al. 2018). A decrease in $F_{v} / F_{m}$ and $F_{v} / F_{0}$ parameters has been reported earlier in cultivated barley compared to wild type under drought stress (Ghotbi-Ravandi et al. 2016). Drought stress inhibited the electron transport rates at the PSII acceptor side as evidenced by decreasing $\mathrm{ET}_{0} / \mathrm{ABS}$ and $\mathrm{ET}_{0} / \mathrm{TR}_{0}$. A higher decrease of these two parameters in modern cultivar New Star is in agreement with significantly higher values of $V_{J}$ and $V_{I}$ of this cultivar. Liu et al. (2020) also reported that drought stress caused a decrease of these parameters in drought-sensitive maize plants. Values of parameter $\mathrm{RE}_{0} / \mathrm{ET}_{0}$ depend on the electrons transferred to PSI from $\mathrm{PQH}_{2}$ and the electron influx from the upper electron carrier (Yan et al. 2013). Unchanged values of parameter $\mathrm{RE}_{0} / \mathrm{ET}_{0}$ in both cultivars and a small decline of $\mathrm{RE}_{0} / \mathrm{ABS}$ at $7 \mathrm{DAS}$ indicated that electron flow was still proceeding normally from $\mathrm{PQH}_{2}$ to the PSI end electron acceptors (Luo et al. 2016). Like in previous reports (Boguszewska-Mańkowska et al. 2018, Botyanszka et al. 2020), our data also showed that $\mathrm{PI}_{\mathrm{ABS}}$ and $\mathrm{PI}_{\text {total }}$ were found to be more sensitive to drought than $F_{v} / F_{m}$. Although the parameter fluorescence quantum yield $\left(\mathrm{F}_{\mathrm{v}} / \mathrm{F}_{\mathrm{m}}\right)$ is the most widely used parameter for the efficiency of PSII, decreasing of this parameter was less pronounced compared to $\mathrm{PI}_{\mathrm{ABS}}$ and $\mathrm{PI}_{\text {total }}$ in both cultivars. Particularly in autochthonous cultivar Crveni hrušt, where the decrease of this parameter was significantly lower only at 7 DAS. $\mathrm{PI}_{\mathrm{ABS}}$ has been used by many researchers to evaluate plants' health status and identify cultivars' tolerance to various abiotic stresses including drought stress (Živčák et al. 2008, Boureima et al. 2012). In this study, drought caused a significant decrease of photosynthetic activity in both investigated cultivars where decreases in $\mathrm{PI}_{\text {total }}$, as water deficit increased, were similar to those observed for $\mathrm{PI}_{\mathrm{ABS}}$. A stronger decline of these parameters during the drought period in modern cultivar New Star confirmed its higher drought sensitivity compared with autochthonous cultivar. In our previous research, we also observed that autochthonous apple cultivar had better photosynthetic efficiency compared to modern apple cultivar under drought conditions (Mihaljević et al. 2021).

In general, drought stress resulted in changes in $\mathrm{Chl}$ fluorescence parameters in both modern and autochthonous cultivars, but these alterations were more pronounced in modern cultivar New Star. A greater increase in the energy dissipation per active reaction centre $\left(\mathrm{DI}_{0} / \mathrm{RC}\right)$ revealed that RCs were inactivated under drought stress because the RCs dissipated most of the energy that was absorbed as heat and not used in the photochemistry of photosynthesis. Autochthonous cultivar Crveni hrušt is capable of better sustaining the photosynthetic electron transport machinery under drought conditions in comparison with the modern cultivar New Star, therefore it has less declining trends of $\mathrm{PI}_{\mathrm{ABS}}$ and $\mathrm{PI}_{\text {total }}$. 
Chl molecules are essential pigments for photosynthesis. A reduction in the Chl content is a common effect of different abiotic stress conditions including drought (Viljevac et al. 2013), therefore it is a reliable indicator of water stress, particularly in stress-sensitive varieties (Guo et al. 2016, Umar and Siddiqui 2018). The total amount of leaf $\mathrm{Chl}$ content [Chl $(a+b)]$ directly influences the photosynthetic capacity of plants and high concentrations of Chl increase photosynthesis. According to our results, we can conclude that in the autochthonous cultivar Crveni hrušt which was the more stress-tolerant cultivar, Chl contents increased and it caused a better stress tolerance of this cultivars. A previous study also reported that Chl content in leaves of tolerant cultivar increased under drought conditions (Mensah et al. 2006) and that tolerant cultivars have a higher $\mathrm{Chl}$ content (Zaefyzadeh et al. 2009).

It is known that drought stress in plants disturbs the photosynthetic electron transport, leading to a decrease in photosynthesis and causing excessive production of ROS (Takahashi and Murata 2008). Oxidative injuries caused by drought stress resulted in lipid peroxidation and MDA content is used to examine the oxidative damage in the cell membranes (Bandurska and Jóźwiak 2010). Increases in the MDA content of the modern cultivar New Star suggest that drought stress induced oxidative damage of the membrane system in this cultivar. Unchanged MDA content in the leaves of autochthonous cultivar during drought treatment did not lead to lipid peroxidation, indicating better protection from oxidative damage. According to $\mathrm{Xu}$ et al. (2008), MDA is one of the best physiological components of drought tolerance in plants and low MDA content was associated with drought tolerance in previous research (Bhardwaj and Yadav 2012). It was reported that an increase in lipid peroxidation of the plants, under stress, may cause Chl degradation (Karimpour 2019). In our study, a significant reduction in Chl content observed in modern cultivar New Star (cultivar with lower photosynthetic performance) was accompanied by increased lipid peroxidation.

Under drought conditions, the modern cultivar New Star showed a significant reduction in WC at an earlier period of drought applied, indicating that the water status in this cultivar was more sensitive to drought stress compared to autochthonous. The increase in WC at 3 and 5 DAS in autochthonous cultivar Crveni hrušt indicates the better acclimation of this cultivar to water stress conditions, probably because of better ability to mention water loss from the leaves. We presumed that higher water content in this cultivar was due to activation of some defense mechanisms and accumulation of some compounds, such as proline, causing a decrease of osmotic potential and increase leaf turgor (Bandurska and Jóźwiak 2010). Our results are consistent with other reports which presented that drought-tolerant plants have higher water content and photosynthetic efficiency (Kumar et al. 2014, Braga et al. 2020).

Conclusion: The water deficit had a significant effect on the photochemical activity of investigated sweet cherry cultivars, reducing photosynthetic apparatus performance. The inhibition of electron transport rate, accompanied by increasing of MDA and decreasing of photosynthetic pigments content, is an indicator of limited photochemistry of PSII in modern cultivar New Star. The autochthonous cultivar Crveni hrušt maintained higher WC, Chl content, photosynthetic efficiency, and lesser oxidative damage during drought stress. Therefore, the autochthonous cultivar showed an advantage over modern in terms of the efficiency of PSII under progressive drought conditions.

\section{References}

Abid M., Ali S., Qi L.K. et al.: Physiological and biochemical changes during drought and recovery periods at tillering and jointing stages in wheat (Triticum aestivum L.). - Sci. Rep.-UK 8: 4615, 2018.

Akhter M.S., Noreen S., Mahmood S. et al.: Influence of salinity stress on PSII in barley (Hordeum vulgare L.) genotypes, probed by chlorophyll $a$ fluorescence. - J. King Saud Univ. Sci. 33: 101239, 2021.

Arslan Ö., Balkan Nalçaiyi A.S., Çulha Erdal Ş et al.: Analysis of drought response of sunflower inbred lines by chlorophyll $a$ fluorescence induction kinetics. - Photosynthetica 58: 348$357,2020$.

Bandurska H., Jóźwiak W.: A comparison of the effects of drought on proline accumulation and peroxidases activity in leaves of Festuca rubra L. and Lolium perenne L. - Acta Soc. Bot. Pol. 79: 111-116, 2010.

Bano H., Athar H.R., Zafar Z.U. et al.: Linking changes in chlorophyll $a$ fluorescence with drought stress susceptibility in mung bean [Vigna radiata (L.) Wilczek]. - Physiol. Plantarum 172: 1244-1254, 2021.

Batra N.G, Sharma V., Kumari N.: Drought-induced changes in chlorophyll fluorescence, photosynthetic pigments, and thylakoid membrane proteins of Vigna radiata. - J. Plant Interact. 9: 712-721, 2014.

Bhardwaj J., Yadav S.K.: Comparative study on biochemical parameters and antioxidant enzymes in a drought tolerant and a sensitive variety of horsegram (Macrotyloma uniflorum) under drought stress. - Am. J. Plant Physiol. 7: 17-29, 2012.

Blanco V., Blaya-Ros P.J., Torres-Sánchez R., Domingo R.: Influence of regulated deficit irrigation and environmental conditions on reproductive response of sweet cherry trees. Plants-Basel 9: 94, 2020.

Boguszewska-Mańkowska D., Pieczyński M., Wyrzykowska A. et al.: Divergent strategies displayed by potato (Solanum tuberosum L.) cultivars to cope with soil drought. - J. Agron. Crop Sci. 204: 13-30, 2018.

Botyanszka L., Zivcak M., Chovancek E. et al.: Chlorophyll fluorescence kinetics may be useful to identify early drought and irrigation effects on photosynthetic apparatus in fieldgrown wheat. - Agronomy 10: 1275, 2020.

Boureima S., Oukarroum A., Diouf M. et al.: Screening for drought tolerance in mutant germplasm of sesame (Sesamum indicum) probing by chlorophyll $a$ fluorescence. - Environ. Exp. Bot. 81: 37-43, 2012.

Braga P.C.S., Martins J.P.R., Bonomo R.: Differential response of photosystem II and I photochemistry in leaves of two Crambe abyssinica Hochst lineages submitted to water deficit. Photosynthetica 58: 1122-1129, 2020.

Cattivelli L., Rizza F., Badeck F.W. et al.: Drought tolerence improvement in crop plants: An integrated view from breeding to genomics. - Field Crop. Res. 105: 1-14, 2008.

Dąbrowski P., Baczewska-Dąbrowska A.H., Kalaji H.M. et al.: 
Exploration of chlorophyll $a$ fluorescence and plant gas exchange parameters as indicators of drought tolerance in perennial ryegrass. - Sensors-Basel 19: 2736, 2019.

Falqueto A.R., da Silva Júnior R.A., Gomes M.T.G. et al.: Effects of drought stress on chlorophyll $a$ fluorescence in two rubber tree clones. - Sci. Hortic.-Amsterdam 224: 238-243, 2017.

Flexas J., Medrano H.: Drought-inhibition of photosynthesis in $\mathrm{C}_{3}$ plants: stomatal and non-stomatal limitations revisited. Ann Bot.-London 89: 183-189, 2002.

Franić M., Jambrović A., Zdunić Z. et al.: Photosynthetic properties of maize hybrids under different environmental conditions probed by the chlorophyll $a$ fluorescence. Maydica 64: M25, 2020.

Ghotbi-Ravandi A.A., Shahbazi M., Pessarakli M., Shariati M.: Monitoring the photosystem II behavior of wild and cultivated barley in response to progressive water stress and rehydration using OJIP chlorophyll $a$ fluorescence transient. - J. Plant Nutr. 39: 1174-1185, 2016.

Goltsev V.N., Kalaji H.M., Paunov M. et al.: Variable chlorophyll fluorescence and its use for assessing physiological condition of plant photosynthetic apparatus. - Russ. J. Plant Physiol. 63: 869-893, 2016.

Gomes M.T.G., da Luz A.C., dos Santos M.R. et al.: Drought tolerance of passion fruit plants assessed by the OJIP chlorophyll $a$ fluorescence transient. - Sci. Hortic.-Amsterdam 142: 49-56, 2012.

Guha A., Sengupta D., Reddy A.R.: Polyphasic chlorophyll $a$ fluorescence kinetics and leaf protein analyses to track dynamics of photosynthetic performance in mulberry during progressive drought. - J. Photoch. Photobio. B 119: 71-83, 2013.

Guo Y.-Y., Yu H.-Y., Kong D.-S. et al.: Effects of drought stress on growth and chlorophyll fluorescence of Lycium ruthenicum Murr. seedlings. - Photosynthetica 54: 524-531, 2016.

Gupta R.: The oxygen-evolving complex: a super catalyst for life on earth, in response to abiotic stresses. - Plant Signal. Behav. 15: 1824721, 2020.

Gururani M.A., Venkatesh J., Tran L.S.P.: Regulation of photosynthesis during abiotic stress-induced photoinhibition. Mol. Plant 8: 1304-1320, 2015.

Je S.M., Kim S.H., Woo S.Y.: Responses of the photosynthetic apparatus of Abies koreana to drought under different light conditions. - Ecol. Res. 33: 413-423, 2018.

Jedmowski C., Bayramov S., Brüggemann W. et al.: Comparative analysis of drought stress effects on photosynthesis of Eurasian and North African genotypes of wild barley. - Photosynthetica 52: 564-573, 2014

Jedmowski C., Brüggemann W.: Imaging of fast chlorophyll fluorescence induction curve (OJIP) parameters, applied in a screening study with wild barley (Hordeum spontaneum) genotypes under heat stress. - J. Photoch. Photobio. B 151: 153-160, 2015.

Kalaji H.M., Govindjee, Bosa K. et al.: Effects of salt stress on photosystem II efficiency and $\mathrm{CO}_{2}$ assimilation of two Syrian barley landraces. - Environ. Exp. Bot. 73: 64-72, 2011.

Kalaji H.M., Jajoo A., Oukarroum A. et al.: Chlorophyll $a$ fluorescence as a tool to monitor physiological status of plants under abiotic stress conditions. - Acta Physiol. Plant. 38: 102, 2016.

Karimpour M.: Effect of drought stress on RWC and chlorophyll content on wheat (Triticum durum L.) genotypes. - World Essays J. 7: 52-56, 2019.

Kelley D.S., Adkins Y., Laugero K.D.: A review of the health benefits of cherries. - Nutrients-Basel 10: 368, 2018.

Krmpot T., Radoš Lj., Vokurka A.: Characterisation of autochthonous sweet cherry genotypes (Prunus avium L.) using SSR markers. - Genetika 52: 43-53, 2020.

Kumar D., Al Hassan M., Naranjo M.A. et al.: Effects of salinity and drought on growth, ionic relations, compatible solutes and activation of antioxidant systems in oleander (Nerium oleander L.). - PLoS ONE 12: e0185017, 2017.

Kumar S., Dwivedi S.K., Singh S.S. et al.. Identification of drought tolerant rice genotype by analysing drought tolerance indices and morpho-physiological traits. - SABRAO J. Breed. Genet. 46: 217-230, 2014.

Lavergne J.: Two types of primary acceptors in chloroplasts photosystem II. - Photobioch. Photobiop. 3: 257-271, 1982.

Lazár D.: The polyphasic chlorophyll a fluorescence rise measured under high intensity of exciting light. - Funct. Plant Biol. 33: 9-30, 2006.

Liang H.Z., Zhu F., Wang R.J. et al.: Photosystem II of Ligustrum lucidum in response to different levels of manganese exposure. - Sci. Rep.-UK 9: 12568, 2019.

Lichtenthaler H.K.: Chlorophylls and carotenoids: pigments of photosynthetic biomembranes. - Method. Enzymol. 148: 350-382, 1987.

Liu J., Li H.J., Guo Y.Y. et al.: Responses of photosynthetic electron transport to drought and re-watering in two maize genotypes. - Russ. J. Plant Physiol. 67: 912-922, 2020.

Lopes D.M.S., Tognella M.M.P., Falqueto A.R., Soares M.L.G.: Salinity variation effects on photosynthetic responses of the mangrove species (Rhizophora mangle L.) growing in natural habitats. - Photosynthetica 57: 1142-1155, 2019.

Luo H.H., Tsimilli-Michael M., Zhang Y.L., Zhang W.F.: Combining gas exchange and chlorophyll $a$ fluorescence measurements to analyze the photosynthetic activity of dripirrigated cotton under different soil water deficits. - J. Integr. Agr. 15: 1256-1266, 2016.

Ma P., Bai T.-H., Ma F.-W.: Effects of progressive drought on photosynthesis and partitioning of absorbed light in apple trees. - J. Integr. Agr. 14: 681-690, 2015.

Maswada H.F., Djanaguiraman M., Prasad P.V.V.: Response of photosynthetic performance, water relations and osmotic adjustment to salinity acclimation in two wheat cultivars. Acta Physiol. Plant. 40: 105, 2018.

Mensah J.K., Obadoni B.O., Eroutor P.G., Onome-Irieguna F.: Simulated flooding and drought effects on germination, growth, and yield parameters of sesame (Sesamum indicum L.). - Afr. J. Biotechnol. 5: 1249-1253, 2006.

Mihaljević I., Viljevac Vuletić M., Šimić D. et al.: Comparative study of drought stress effects on traditional and modern apple cultivars. - Plants-Basel 10: 561, 2021.

Mondini L., Noorani A., Pagnotta M.A.: Assessing plant genetic diversity by molecular tools. - Diversity 1: 19-35, 2009.

Oukarroum A., El Madidi S., Schansker G., Strasser R.J.: Probing the responses of barley cultivars (Hordeum vulgare L.) by chlorophyll $a$ fluorescence OLKJIP under drought stress and re-watering. - Environ. Exp. Bot. 60: 438-446, 2007.

Paunov M., Koleva L., Vassilev A.: Effects of different metals on photosynthesis: cadmium and zinc affect chlorophyll fluorescence in durum wheat. - Int. J. Mol. Sci. 19: 787, 2018.

Pereira W.E., de Siqueira D.L., Martínez C.A., Puiatti M.: Gas exchange and chlorophyll fluorescence in four citrus rootstocks under aluminium stress. - J. Plant Physiol. 157: 513-520, 2000.

Pérez-Pérez J.G., Romero P., Navarro J.M., Botía P.: Response of sweet orange cv 'Lane late' to deficit irrigation in two rootstocks. I: Water relations, leaf gas exchange and vegetative growth. - Irrigation Sci. 26: 415-425, 2008.

Plich J., Boguszewska-Mańkowska D., Marczewski W.: Relations between photosynthetic parameters and droughtinduced tuber yield decrease in Katahdin-derived potato 
cultivars. - Potato Res. 63: 463-477, 2020.

Radoš Lj., Krmpot T., Begović F.: Fruit characteristics of autochthonous sweet cherry cultivars (Prunus avium L.) from the Banjaluka region. - Agro-know. J. 18: 285-292, 2017.

Redillas M.C.F.R., Strasser R.J., Jeong J.S. et al.: The use of JIP test to evaluate drought-tolerance of transgenic rice overexpressing OsNAC10. - Plant Biotechnol. Rep. 5: 169175, 2011.

Sousaraei N., Mashayekhi K., Mousavizadeh S.J. et al.: Screening of tomato landraces for drought tolerance based on growth and chlorophyll fluorescence analyses. - Hortic. Environ. Biote. 62: 521-535, 2021.

Stirbet A.: Excitonic connectivity between photosystem II units: what is it, and how to measure it? - Photosynth. Res. 116: 189-214, 2013.

Stirbet A., Govindjee G.: On the relation between the Kautsky effect (chlorophyll $a$ fluorescence induction) and photosystem II: basics and applications of the OJIP fluorescence transient. - J. Photoch. Photobio. B 104: 236-257, 2011.

Stirbet A., Lazár D., Kromdijk J., Govindjee G.: Chlorophyll $a$ fluorescence induction: Can just a one-second measurement be used to quantify abiotic stress responses? - Photosynthetica 56: 86-104, 2018.

Strasser B.J.: Donor side capacity of photosystem II probed by chlorophyll $a$ fluorescence transients. - Photosynth. Res. 52: 147-155, 1997.

Strasser B.J., Strasser R.J.: Measuring fast fluorescence transients to address environmental questions: The JIP test. - In: Mathis P. (ed.): Photosynthesis: From Light to Biosphere. Vol. 5. Pp. 977-980. Kluwer Academic Publishers, Dordrecht 1995.

Strasser R.J., Tsimilli-Michael M., Srivastava A.: Analysis of the chlorophyll $a$ fluorescence transient. - In: Papageorgiou G.C., Govindjee (ed.): Chlorophyll $a$ Fluorescence: A Signature of Photosynthesis. Advances in Photosynthesis and Respiration. Pp. 321-362. Springer, Dordrecht 2004.

Takahashi S., Murata N.: How do environmental stresses accelerate photoinhibition? - Trends Plant Sci. 13: 178-182, 2008.
Tsuchida Y., Negoro K., Hishiike M.: Effect of initiation timing of drought stress on carbohydrate content and vegetative growth in Japanese apricot (Prunus mume Sieb. et Zucc.) 'Nanko'. - J. Jpn. Soc. Hortic. Sci. 80: 19-25, 2011.

Umar M., Siddiqui Z.S.: Physiological performance of sunflower genotypes under combined salt and drought stress environment. - Acta Bot. Croat. 77: 36-44, 2018.

Verma S., Dubey R.S.: Lead toxicity induces lipid peroxidation and alters the activities of antioxidant enzymes in growing rice plants. - Plant Sci. 164: 645-655, 2003.

Viljevac M., Dugalić K., Mihaljević I. et al.: Chlorophylls content and photosynthetic efficiency in two sour cherry (Prunus cerasus L.) genotypes under drought stress. - Acta Bot. Croat. 72: 221-235, 2013.

Xu Z.Z., Zhou G.S., Wang Y.L. et al.: Changes in chlorophyll fluorescence in maize plants with imposed rapid dehydration at different leaf ages. - J. Plant Growth Regul. 27: 83-92, 2008.

Yan K., Chen P., Shao H. et al.: Dissection of photosynthetic electron transport process in sweet sorghum under heat stress. - PLoS ONE 8: e62100, 2013.

Yuan J., Xu M., Duan W. et al.: Effects of whole-root and halfroot water stress on gas exchange and chlorophyll fluorescence parameters in apple trees. - J. Am. Soc. Hortic. Sci. 138: 395402, 2013.

Yusuf M.A., Kumar D., Rajwanshi R. et al.: Overexpression of $\gamma$-tocopherol methyl transferase gene in transgenic Brassica juncea plants alleviates abiotic stress: physiological and chlorophyll a fluorescence measurements. - BBABioenergetics 1797: 1428-1438, 2010.

Zaefyzadeh M., Quliyev R.A., Babayeva S.M., Abbasov M.A.: The effect of the interaction between genotypes and drought stress on the superoxide dismutase and chlorophyll content in durum wheat landraces. - Turk. J. Biol. 33: 1-7, 2009.

Zushi K., Matsuzoe N.: Using of chlorophyll $a$ fluorescence OJIP transients for sensing salt stress in the leaves and fruits of tomato. - Sci. Hortic.-Amsterdam 219: 216-221, 2017.

Živčák M., Brestič M., Olšovská K., Slamka P.: Performance index as a sensitive indicator of water stress in Triticum aestivum L. - Plant Soil Environ. 54: 133-139, 2008.

Appendix. Definitions and calculations of the JIP test parameters used in the present study.

Technical fluorescence parameters

\begin{tabular}{|c|c|}
\hline $\mathrm{F}_{0}$ & Initial fluorescence intensity at $50 \mu \mathrm{s}$, when all PSII RCs are open \\
\hline $\mathrm{F}_{\mathrm{m}}$ & Maximal fluorescence intensity, when all PSII RCs are closed \\
\hline $\mathrm{F}_{\mathrm{v}}=\mathrm{F}_{\mathrm{m}}-\mathrm{F}_{0}$ & Maximal variable fluorescence \\
\hline $\mathrm{V}_{\mathrm{J}}=\left(\mathrm{F}_{\mathrm{J}}-\mathrm{F}_{0}\right) /\left(\mathrm{F}_{\mathrm{m}}-\mathrm{F}_{0}\right)$ & Relative variable fluorescence at the J-step $(2 \mathrm{~ms})$ \\
\hline $\mathrm{V}_{\mathrm{I}}=\left(\mathrm{F}_{\mathrm{I}}-\mathrm{F}_{0}\right) /\left(\mathrm{F}_{\mathrm{m}}-\mathrm{F}_{0}\right)$ & Relative variable fluorescence at the I-step ( $30 \mathrm{~ms})$ \\
\hline $\mathrm{S}_{\mathrm{m}}=\operatorname{Area} /\left(\mathrm{F}_{\mathrm{m}}-\mathrm{F}_{0}\right)$ & $\begin{array}{l}\text { Normalized total complementary area above the OJIP transient (reflecting single- } \\
\text { turnover } \mathrm{Q}_{\mathrm{A}} \text { reduction events) }\end{array}$ \\
\hline $\mathrm{F}_{\mathrm{v}} / \mathrm{F}_{0}=\mathrm{k}_{\mathrm{P}} / \mathrm{k}_{\mathrm{N}}=\mathrm{TR}_{0} / \mathrm{DI}_{0}$ & $\begin{array}{l}\text { The ratio between the trapping flux and energy dissipation flux of PSII; where } \mathrm{k}_{\mathrm{P}} \text { and } \\
\mathrm{k}_{\mathrm{N}} \text { are the photochemical and nonphotochemical de-excitation rate constants of PSII } \\
\text { antenna in dark-adapted samples }\end{array}$ \\
\hline $\mathrm{M}_{0}=4\left(\mathrm{~F}_{300 \mu \mathrm{s}}-\mathrm{F}_{0}\right) /\left(\mathrm{F}_{\mathrm{m}}-\mathrm{F}_{0}\right)$ & Initial slope of the fluorescence transient \\
\hline \multicolumn{2}{|l|}{ Quantum efficiencies or flux ratios } \\
\hline $\mathrm{TR}_{0} / \mathrm{ABS}=\mathrm{F}_{\mathrm{v}} / \mathrm{F}_{\mathrm{m}}=\left[1-\left(\mathrm{F}_{0} / \mathrm{F}_{\mathrm{m}}\right)\right]$ & Maximum quantum yield of primary PSII photochemistry \\
\hline $\mathrm{ET}_{0} / \mathrm{ABS}=\varphi_{\mathrm{E} 0}=\left(1-\mathrm{F}_{0} / \mathrm{F}_{\mathrm{m}}\right)\left(1-\mathrm{V}_{\mathrm{J}}\right)$ & Quantum yield for electron transport from $\mathrm{Q}_{\mathrm{A}}^{-}$to $\mathrm{PQ}$ \\
\hline $\mathrm{RE}_{0} / \mathrm{ET}_{0}=\delta_{0}=\left(1-\mathrm{V}_{\mathrm{I}}\right)\left(1-\mathrm{V}_{\mathrm{J}}\right)$ & The efficiency with which an electron from $\mathrm{PQH}_{2}$ is transferred to final PSI acceptors \\
\hline $\mathrm{ET}_{0} / \mathrm{TR}_{0}=\psi_{\mathrm{E} 0}=1-\mathrm{V}_{\mathrm{J}}$ & $\begin{array}{l}\text { Probability that trapped exciton moves an electron into the electron transport chain } \\
\text { beyond } \mathrm{Q}_{\mathrm{A}}^{-}\end{array}$ \\
\hline
\end{tabular}


$\mathrm{RE}_{0} / \mathrm{ABS}=\varphi_{\mathrm{R} 0}=\varphi_{\mathrm{P} 0} \times \psi_{\mathrm{E} 0} \times \delta_{\mathrm{R} 0}$

Specific fluxes (per active PSII)

$\mathrm{ABS} / \mathrm{RC}=\mathrm{M}_{0}\left(1 / \mathrm{V}_{\mathrm{J}}\right)\left(1 / \varphi_{\mathrm{P} 0}\right)$

$\mathrm{TR}_{0} / \mathrm{RC}=\mathrm{M}_{0}\left(1 / \mathrm{V}_{\mathrm{J}}\right)$

$\mathrm{ET}_{0} / \mathrm{RC}=\mathrm{M}_{0}\left(1 / \mathrm{V}_{\mathrm{J}}\right) \times \psi_{0}$

$\mathrm{DI}_{0} / \mathrm{RC}=\mathrm{ABS} / \mathrm{RC}-\mathrm{TR}_{0} / \mathrm{RC}$

$\mathrm{RE}_{0} / \mathrm{RC}=\mathrm{M}_{0}\left(1 / \mathrm{V}_{\mathrm{J}}\right) \times \psi_{\mathrm{E} 0} \times \delta_{\mathrm{R} 0}$

Performance indexes

$\mathrm{PI}_{\mathrm{ABS}}=(\mathrm{RC} / \mathrm{ABS})\left(\mathrm{TR}_{0} / \mathrm{DI}_{0}\right)\left[\mathrm{ET}_{0} /\left(\mathrm{TR}_{0}-\mathrm{ET}_{0}\right)\right]$

$\mathrm{PI}_{\text {total }}=\mathrm{PI}_{\mathrm{ABS}}\left[\left(\mathrm{RE}_{0} / \mathrm{ET}_{0}\right) /\left(1-\mathrm{RE}_{0} / \mathrm{ET}_{0}\right)\right]$
Quantum yield for reduction of end electron acceptors at the PSI acceptor side

Absorption flux (of antenna Chls) per RC

Trapped energy flux per RC

Electron transport flux per RC

Dissipated energy flux per RC

Electron flux reducing end electron acceptors at the PSI acceptor side, per RC

(C) The authors. This is an open access article distributed under the terms of the Creative Commons BY-NC-ND Licence.

Performance index for energy conservation from exciton to the reduction of PSI end acceptors 